\title{
Corpus gastritis is protective against reflux oesophagitis
}

\author{
H B El-Serag, A Sonnenberg, M M Jamal, J M Inadomi, L A Crooks, R M Feddersen
}

\begin{abstract}
Background-Gastric acid is important in the pathogenesis of reflux oesophagitis. Acid production by the gastric corpus is reduced in corpus gastritis.

Aims-To determine whether corpus gastritis protects against reflux oesophagitis. Methods-Patients presenting for elective oesophagogastroduodenoscopy were studied. Two biopsy specimens were taken from the antrum, corpus, and cardia and stained with haematoxylin/eosin and DiffQuick II stains. The presence and severity of gastritis were graded according to a modified updated Sydney classification.

Results-Of 302 patients, 154 had endoscopic signs of reflux oesophagitis. There was no difference between patients with and controls without oesophagitis in the overall infection rates with Helicobacter pylori. Acute or chronic corpus gastritis occurred less often in patients with than those without reflux oesophagitis. Compared with controls, corpus gastritis was less severe in patients with reflux oesophagitis. The presence of acute or chronic gastritis in the corpus was significantly correlated with either type of gastritis in other areas of the stomach. In a multivariate logistic regression, age, sex, smoking status, and the presence of chronic corpus gastritis all exerted a significant influence on the presence of reflux oesophagitis. Chronic corpus gastritis was associated with a $54 \%$ reduced risk for reflux oesophagitis.
\end{abstract}

Conclusions-While infection with $H$ pylori alone may not affect the occurrence of reflux oesophagitis, the development of chronic corpus gastritis seems to be protective.

(Gut 1999;45:181-185)

Department of

Veterans Affairs

Medical Centre,

University of New

Mexico, Albuquerque,

New Mexico, USA

H B El-Serag

A Sonnenberg

M M Jamal

$\mathrm{J} M$ Inadomi

L A Crooks

R M Feddersen

Correspondence to: Dr A Sonnenberg, Department of Veterans Affairs Medical Centre $111 \mathrm{~F}$ 1501 San Pedro Drive SE, Albuquerque, New Mexico 87108, USA.

Accepted for publication 13 January 1999

Gastric acid is an important determinant in the development of reflux oesophagitis secondary to gastro-oesophageal reflux (GORD). ${ }^{1}$ The proteolytic enzyme pepsin becomes active in the gastric refluxate and causes necrosis of the oesophageal mucosa only if the $\mathrm{pH}$ value of the refluxate drops below $\mathrm{pH} 4 .^{2}$ The combination of gastric hydrochloric acid and pepsin leads to severe oesophagitis in animal as well as human models. ${ }^{3}$ Strong inhibition of gastric secretion of acid represents the mainstay in current management of reflux oesophagitis. ${ }^{4}$ The corpus region of the stomach is the primary acid producing region by virtue of the abundant parietal cell content of its glands. ${ }^{5}$ Gastritis and atrophy of the gastric corpus can result in decreased acid output. ${ }^{6}$ Both conditions may be caused by Helicobacter pylori infection of the gastric mucosa. In a prospective case control study, we tested the hypothesis that corpus gastritis protects against reflux oesophagitis.

\section{Methods}

The study was approved by the Research Committee of the Department of Veterans Affairs (VA) Medical Centre in Albuquerque, New Mexico. Prior to entering the study, all subjects gave written informed consent. All subjects referred for elective upper gastrointestinal endoscopy to the Albuquerque VA Medical Centre and the University of New Mexico Medical Centre were considered eligible to be enrolled into the study. Prior to the study, we estimated a $40 \%$ prevalence rate of corpus gastritis in patients with reflux oesophagitis. In order to detect a $20 \%$ difference between patients and controls with an $\alpha$ error of $5 \%$ and a $\beta$ error of $10 \%, 140$ people needed to be recruited into each group of patients and controls. Our intention was to enrol similar numbers of patients and controls. Therefore, we were eager to include all consecutive patients with erosive oesophagitis, but less so with regard to patients without oesophagitis. Subjects were excluded from the study if they underwent emergency procedures, for instance, for gastrointestinal bleeding. Subjects were also excluded if no gastrointestinal biopsy specimens could be obtained safely during endoscopy because of an underlying coagulation disorder, or because the physician assumed that performing biopsies would unduly prolong the endoscopic procedure, for instance, in patients with a compromised cardiopulmonary status. Subjects participating in other prospective randomised clinical trials were not included in the present protocol. The study was conducted between January and July 1997.

A routine oesophagogastroduodenoscopy
A performed in all subjects using an Olympus GIF-130 instrument. Based on the endoscopic appearance of the oesophageal mucosa, the patient population was broken down into case and control subjects with and without reflux oesophagitis, respectively. Reflux oesophagitis was graded as follows ${ }^{7}$ : grade 1 - single erosions; grade 2-conflent erosions;

Abbreviations used in this paper: GORD, gastro-oesophageal reflux disease. 
Table 1 Demographic characteristics and distribution of gastritis in patients with and controls without reflux oesophagitis

\begin{tabular}{|c|c|c|c|c|c|}
\hline & $\begin{array}{l}1 \text { Oesophagitis and } \\
\text { Barrett's }(n=154)\end{array}$ & $\begin{array}{l}2 \text { Erosive oesophagitis } \\
(n=116)\end{array}$ & $\begin{array}{l}3 \text { Control subjects } \\
(n=148)\end{array}$ & $\begin{array}{l}1 \text { versus } 3 \\
\text { p value }\end{array}$ & $\begin{array}{l}2 \text { versus } 3 \\
p \text { value }\end{array}$ \\
\hline Mean age in years (SD) & $57(14)$ & $58(14)$ & $54(15)$ & 0.0512 & 0.0363 \\
\hline \multicolumn{6}{|l|}{$\operatorname{Sex}(\%)$} \\
\hline Men & $120(78 \%)$ & $91(78 \%)$ & $92(62 \%)$ & \multirow[t]{2}{*}{0.0028} & \multirow[t]{2}{*}{0.0044} \\
\hline Women & $34(22 \%)$ & $25(22 \%)$ & $56(38 \%)$ & & \\
\hline \multicolumn{6}{|l|}{ Race (\%) } \\
\hline White & $64(42 \%)$ & $65(56 \%)$ & $63(43 \%)$ & \multirow[t]{3}{*}{0.6002} & \multirow[t]{3}{*}{0.0806} \\
\hline Hispanic & $71(46 \%)$ & $45(39 \%)$ & $72(49 \%)$ & & \\
\hline Others & $19(12 \%)$ & $6(5 \%)$ & $13(9 \%)$ & & \\
\hline H pylori infection ${ }^{\star}$ & $67(44 \%)$ & $46(40 \%)$ & $64(43 \%)$ & 0.9594 & 0.5573 \\
\hline \multicolumn{6}{|l|}{ Gastritis distribution (\%) } \\
\hline Antrum acute gastritis $†$ & $49(32 \%)$ & $31(27 \%)$ & $55(37 \%)$ & 0.3924 & 0.0725 \\
\hline Antrum chronic gastritis $\dagger$ & $83(55 \%)$ & $61(53 \%)$ & $97(66 \%)$ & 0.0618 & 0.0331 \\
\hline Corpus acute gastritis & $39(25 \%)$ & $22(19 \%)$ & $54(36 \%)$ & 0.0357 & 0.0018 \\
\hline Corpus chronic gastritis & $74(48 \%)$ & $50(43 \%)$ & $96(65 \%)$ & 0.0032 & 0.0004 \\
\hline Cardia acute gastritis $\ddagger$ & $42(29 \%)$ & $6(5 \%)$ & $50(35 \%)$ & 0.2728 & 0.0000 \\
\hline Cardia chronic gastritis $\ddagger$ & $77(54 \%)$ & $57(49 \%)$ & $93(66 \%)$ & 0.0374 & 0.0071 \\
\hline
\end{tabular}

${ }^{\star}$ By histology of biopsy specimens from any part of the stomach. †Antral biopsy specimens available for 151 patients and 148 controls. $\ddagger$ Cardia biopsy specimens available for 143 patients and 141 controls.

grade 3-circumferential erosions; and grade 4-ulcers, strictures, or Barrett's oesophagus. The gastro-oesophageal junction was identified by the junction of the tubular oesophagus with the most proximal gastric folds and the position of the lower oesophageal sphincter. Any length of columnar mucosa that extended above the gastro-oesophageal junction into the tubular oesophagus was recorded as endoscopic suspicion for Barrett's oesophagus and biopsy specimens were obtained from this area. Barrett's oesophagus was defined by the visual presence of columnar mucosa within the tubular oesophagus plus the histological presence of intestinal metaplasia in these areas. In addition, two gastric biopsy specimens were obtained from the antrum, corpus, and cardia. The antrum biopsy specimens were taken within 2 $\mathrm{cm}$ from the pylorus. The corpus biopsy specimens were obtained from the largest folds on the gastric greater curvature. The cardiac biopsy specimens were taken within $2 \mathrm{~cm}$ below the gastro-oesophageal junction. All specimens were obtained using a standard Microvasive biopsy forceps. Three separate bottles containing $10 \%$ neutral formalin were used to transfer each pair of specimens.

The gastric biopsy specimens were embedded in paraffin wax, and $3 \mu \mathrm{m}$ sections were obtained. Three to four sections were stained

Table 2 Histology of the gastric corpus in patients with and controls without reflux oesophagitis

\begin{tabular}{|c|c|c|c|c|c|}
\hline & $\begin{array}{l}1 \text { Oesophagitis } \\
\text { and Barrett's } \\
(n=154)\end{array}$ & $\begin{array}{l}2 \text { Erosive } \\
\text { oesophagitis } \\
(n=116)\end{array}$ & $\begin{array}{l}3 \text { Control } \\
\text { subjects } \\
(n=148)\end{array}$ & $\begin{array}{l}1 \text { versus } 3 \\
\text { p value }\end{array}$ & $\begin{array}{l}2 \text { versus } 3 \\
p \text { value }\end{array}$ \\
\hline \multicolumn{6}{|c|}{ Acute gastritis } \\
\hline Grade 0 & $115(75 \%)$ & $94(81 \%)$ & $94(64 \%)$ & 0.0383 & 0.0013 \\
\hline Grade 1 & $32(21 \%)$ & $20(17 \%)$ & $37(25 \%)$ & & \\
\hline Grade 2 & $7(5 \%)$ & $2(2 \%)$ & $17(11 \%)$ & & \\
\hline \multicolumn{6}{|c|}{ Chronic gastritis } \\
\hline Grade 0 & $80(52 \%)$ & $66(57 \%)$ & $52(35 \%)$ & 0.0116 & 0.0011 \\
\hline Grade 1 & $52(34 \%)$ & $38(33 \%)$ & $64(43 \%)$ & & \\
\hline Grade 2 & $22(14 \%)$ & $12(10 \%)$ & $32(22 \%)$ & & \\
\hline \multicolumn{6}{|l|}{ Atrophy } \\
\hline Grade 0 & $151(98 \%)$ & $115(99 \%)$ & $136(92 \%)$ & 0.0357 & 0.0249 \\
\hline Grade 1 & $3(2 \%)$ & $1(1 \%)$ & $9(6 \%)$ & & \\
\hline Grade 2 & $0(0 \%)$ & $0(0 \%)$ & $3(2 \%)$ & & \\
\hline \multicolumn{6}{|c|}{ Intestinal metaplasia } \\
\hline Absent & $147(95 \%)$ & $111(96 \%)$ & $135(91 \%)$ & 0.1387 & 0.1524 \\
\hline Present & $7(5 \%)$ & $5(4 \%)$ & $13(9 \%)$ & & \\
\hline \multicolumn{6}{|c|}{ H pylori infection } \\
\hline Grade 0 & $101(66 \%)$ & $80(69 \%)$ & $93(63 \%)$ & 0.6078 & 0.5330 \\
\hline Grade 1 & $37(24 \%)$ & $27(23 \%)$ & $39(26 \%)$ & & \\
\hline Grade 2 & $16(10 \%)$ & $9(8 \%)$ & $16(11 \%)$ & & \\
\hline
\end{tabular}

with haematoxylin and eosin and one section with Diff-Quick II (Dade) stain for the detection of Helicobacter pylori. Two experienced pathologists examined the slides, one pathologist at each hospital. The presence of gastritis was classified according to the updated Sydney classification, ${ }^{8}$ which was modified for the purpose of this study. Acute gastritis (activity), defined by the presence of polymorphonuclear cells within the lamina propria, was graded as 0 -absent, 1 -mild, and 2-severe gastritis. Chronic gastritis, defined by the presence of mononuclear cells within the lamina propria, was graded as 0 - absent, 1 -mild, and 2 - severe gastritis. The presence of $H$ pylori was graded as 0 -absent, 1 -mild, and 2 - heavy density of microorganisms. The presence of atrophy was graded as 0 -absent, 1 - mild, and 2-severe atrophy. The absence or presence of intestinal metaplasia was recorded as 0 or 1 , respectively. If any of the two specimens from the same gastric region showed different scores, only the higher score was considered in the analysis.

A two tailed unpaired $t$ test was used to compare the mean ages of the case and control population. For all other univariate comparisons between case and control subjects, $\chi^{2}$ tests were used. The strengths of the correlations between each two types of gastritis were assessed by Spearman's correlation coefficient for ranked variables. A logistic regression analysis was used for the multivariate analysis of risk factors associated with reflux oesophagitis. The presence of reflux oesophagitis served as the outcome variable, while any of the other demographic characteristics, such as age, sex, smoking status, or gastritis parameters served as predictor variables.

\section{Results}

A total 342 patients was initially enrolled into the study. Forty patients were excluded for the following reasons: presence of a bleeding lesion that precluded biopsy $(n=11)$, early termination of the procedure due to patient discomfort $(n=10)$, lack of corpus biopsy specimens $(n=8)$, postgastrectomy $(n=5)$, impassable oesophageal stricture $(n=3)$, and gastric cancer $(n=3)$. A total of 302 patients was included in 
Table 3 Correlations among various types of gastritis in patients with reflux oesophagitis

\begin{tabular}{lllllll}
\hline Type of gastritis & $\begin{array}{l}\text { Antrum } \\
\text { acute } \\
\text { gastritis }\end{array}$ & $\begin{array}{l}\text { Antrum } \\
\text { chronic } \\
\text { gastritis }\end{array}$ & $\begin{array}{l}\text { Corpus } \\
\text { acute } \\
\text { gastritis }\end{array}$ & $\begin{array}{l}\text { Corpus } \\
\text { chronic } \\
\text { gastritis }\end{array}$ & $\begin{array}{l}\text { Cardia } \\
\text { acute } \\
\text { gastritis }\end{array}$ & $\begin{array}{l}\text { Cardia } \\
\text { chronic } \\
\text { gastritis }\end{array}$ \\
\hline Antrum acute gastritis & 1 & & & & & \\
Antrum chronic gastritis & 0.61 & 1 & & & & \\
Corpus acute gastritis & 0.53 & 0.48 & 1 & & & \\
Corpus chronic gastritis & 0.56 & 0.69 & 0.64 & 1 & 1 & \\
Cardia acute gastritis & 0.57 & 0.48 & 0.66 & 0.57 & 0.60 & 1 \\
Cardia chronic gastritis & 0.51 & 0.65 & 0.56 & 0.65 & \\
\hline
\end{tabular}

The values represent Spearman's $r$; all values are significant at $\mathrm{p}<0.0001$.

the final analysis. Of those, 154 case subjects presented with endoscopic evidence of reflux oesophagitis, while the remainder of 148 control subjects had no endoscopic signs of reflux oesophagitis. In 52 case subjects, reflux oesophagitis was classified as grade 1 , in 19 cases as grade 2 , in eight cases as grade 3 , and in 75 cases as grade 4. Barrett's oesophagus was found in 73 case subjects, of whom 33 presented with a short segment of less than $3 \mathrm{~cm}$, and 40 with a long segment of oesophageal metaplasia. Of 73 patients with Barrett's oesophagus, 38 presented without erosions or strictures. In subsequent analyses, controls were compared with the total case population of all reflux patients $(n=154)$ or with the subset of patients harbouring erosive oesophagitis $(\mathrm{n}=116)$, excluding the 38 patients who presented with Barrett's oesophagus only. Patients with reflux oesophagitis were slightly older than controls without oesophagitis. There were more men and more whites among patients with reflux oesophagitis than among controls. The overall infection rate with $H$ pylori, detected in any of the six gastric biopsy specimens, was similar in patients and controls (table 1).

Corpus biopsy specimens were available for all 302 study patients. Antral specimens were available in 298 patients $(99 \%)$ and cardiac specimens in 283 patients (94\%). Table 1 shows the proportions of patients and controls with acute or chronic gastritis by gastric region, irrespective of its grade. Acute and chronic gastritis tended to be less frequent in patients with reflux oesophagitis compared with controls. In general, the difference between patients and controls became more pronounced if the case population was limited to patients with erosive oesophagitis. Chronic and acute corpus gastritis were both significantly less common in patients with oesophagitis. The difference between patients and controls was less striking with respect to gastritis of the antrum or cardia.

Table 4 Risk factors for reflux oesophagitis

\begin{tabular}{lclll}
\hline Risk factor & Odds ratio & 95\% confidence interval & Wald's $\chi^{2}$ & p Value \\
\hline Outcome: oesophagitis and Barrett's oesophagus & & & \\
Age (per decade) & 1.22 & $(1.01-1.48)$ & 4.297 & 0.0382 \\
Sex (male versus female) & 2.10 & $(1.19-3.73)$ & 6.466 & 0.0110 \\
Smoking status & 1.94 & $(1.06-3.56)$ & 4.586 & 0.0322 \\
Chronic corpus gastritis & 0.46 & $(0.27-0.79)$ & 7.925 & 0.0049 \\
Outcome: erosive oesophagitis alone & 1.27 & $(1.03-1.56)$ & & \\
Age (per decade) & 2.03 & $(1.07-3.84)$ & 4.022 & 0.0250 \\
Sex (male versus female) & 1.50 & $(0.77-2.94)$ & 1.427 & 0.0301 \\
Smoking status & 0.34 & $(0.19-0.61)$ & 12.803 & 0.2323 \\
Chronic corpus gastritis & & & & \\
\hline
\end{tabular}

Odds ratios and their significance were calculated by multiple logistic regression analysis, using as outcome variable all types of reflux disease or erosive oesophagitis alone.
Table 2 contains a more detailed breakdown of corpus gastritis by type and grade among patients with and controls without reflux oesophagitis. Compared with controls, larger proportions of patients with reflux oesophagitis were free of acute or chronic corpus gastritis, the patient-control difference being more striking with respect to chronic gastritis. In addition, the activity and severity of both types of gastritis were more pronounced in controls than patients. Atrophy and intestinal metaplasia tended to be slightly more common in controls without reflux oesophagitis. Similar patterns were found in comparisons of both types of patient population with the control population. Grading of $H$ pylori infection of the corpus mucosa by density of organisms failed to reveal any difference between patients and controls. Overall, none of 90 patients without any form of gastritis were found to harbour $H$ pylori, while the organism was detected histologically in 131 of 212 patients with gastritis (Spearman's correlation $r=0.57, \mathrm{p}<0.0001)$. It might suspected that treatment with proton pump inhibitors suppressed $H$ pylori; however, the infection rates of $34 \%$ and $47 \%$ were not significantly different in subjects with and without such treatment, respectively.

Table 3 is a correlation matrix of different forms of gastritis in patients with reflux oesophagitis. Different forms of gastritis tended to cluster in the same individual patients, as evidenced by the highly significant Spearman correlation coefficients. Two trends could be discerned. Firstly, the correlations seemed to be stronger among gastritis of any type from the same gastric region, such as acute and chronic gastritis of the antrum. Secondly, the correlations also seemed to be stronger among gastritis of the same type from different gastric regions, such as chronic gastritis of the antrum and chronic gastritis of the corpus. However, these trends did not reach statistical significance. Correlation coefficients similar to those in table 3 were observed in control subjects without reflux oesophagitis (data not shown).

Table 4 shows the results of the multiple logistic regression analysis, using as outcome variable the presence of any reflux disease (erosive oesophagitis plus Barrett's oesophagus) or erosive oesophagitis only. Several models were tested and the most parsimonious one is presented here. Because of the significant correlations among various types of gastritis (table 3), only one type of gastritis was analysed at a time. Consistent with the results of the univariate analyses, chronic corpus gastritis yielded the best model (the highest log likelihood ratio). According to the multivariate model of table 4, chronic corpus gastritis was associated with a $54 \%$ reduced risk for reflux oesophagitis (95\% confidence interval: 21 to $73 \%)$. The reduction was even more pronounced if the analysis was restricted to erosive oesophagitis alone (66\%; 95\% confidence interval: 39 to $81 \%$ ). Tobacco smoking and male sex were stronger risk factors in the first regression, consistent with their particularly 
strong influence on the occurrence of Barrett's oesophagus.

\section{Discussion}

In this study, corpus gastritis was found less frequently in patients with reflux oesophagitis than in those without oesophagitis. Chronic corpus gastritis was associated with a 54\% reduction in the risk for reflux oesophagitis. Acute corpus gastritis was also protective against oesophagitis, but to a lesser degree than the chronic form. Moreover, both types of corpus gastritis tended to be less severe in patients with reflux oesophagitis.

Contact of the oesophageal lining with acid is crucial for the development of reflux symptoms, as well as mucosal damage. ${ }^{1}$ Although most subjects with reflux oesophagitis do not hypersecrete gastric acid or pepsin, ${ }^{910}$ some patients with refractory reflux disease present evidence of increased acid and pepsin output. ${ }^{4}$ Exposure of the oesophageal mucosa to hydrochloric acid alone results in injuries that are particularly severe, if the $\mathrm{pH}$ value is less than $1.3 .{ }^{11}$ The severity of oesophagitis correlates with the time of acid exposure. ${ }^{12}$ Moreover, healing of reflux oesophagitis is achieved in most patients if their gastric acid output is suppressed below $1 \mathrm{mEq} / \mathrm{h} .{ }^{4} \mathrm{The}$ presence of acid is also necessary for other substances of the gastric refluxate to exert their injurious influence. For instance, pepsin becomes activated only at $\mathrm{pH}$ levels less than 4 . The combination of hydrochloric acid and pepsin produces more severe oesophagitis than acid alone. ${ }^{3}$ The conjugated bile salts of duodenogastro-oesophageal reflux become mostly undissociated and membrane permeable molecules at an acidic $\mathrm{pH} .{ }^{13}$

$H$ pylori is the commonest known cause of gastritis. The influence of $H$ pylori infection on gastric acid secretion is rather complex and depends, in part, on the type of ensuing gastritis. $H$ pylori itself produces acid inhibitory proteins, ${ }^{14}$ while the infection induced inflammation generates interleukin $1 \beta$, which is a potent inhibitor of acid secretion. ${ }^{15}{ }^{16}$ In some of the patients infected by $H$ pylori, the organism colonises primarily the antrum, resulting in an antrum dominant gastritis characterised by increased gastrin and acid secretion. Such patients may respond to successful eradication of $H$ pylori with reduced acid secretion. ${ }^{17}$ In other groups of patients, $H$ pylori infection spreads from the antrum towards more proximal parts of the stomach. The corpus is the main acid producing region of the stomach. ${ }^{5}$ Corpus gastritis has been linked to reduced gastric acid secretion, the extent and severity of the gastritis being inversely related to the maximum gastric acid output. ${ }^{6}$ Eradication of $H$ pylori in corpus dominant gastritis may be associated with an increased acid secretion. ${ }^{18} 19$ El-Omar et al investigated 16 hypochlorhydric subjects who concomitantly harboured $H$ pylori related corpus dominant gastritis. ${ }^{18}$ Eradication of $H$ pylori led to a resolution of the corpus gastritis and recovery of gastric acid secretion within six months after treatment. Atrophy or intestinal metaplasia did not resolve after treatment. ${ }^{18}$ Gutierrez et al showed a correlation between the improvement in the gastritis score and increased gastric acid secretion after antibiotic therapy. ${ }^{19}$ The increased acid output after $H$ pylori eradication may become clinically significant: Labenz et al followed patients with duodenal ulcer for three years after antibiotic treatment of $H$ pylori infection. ${ }^{20}$ The incidence of reflux oesophagitis was $26 \%$ after eradication of $H$ pylori compared with $13 \%$ in patients with persistent infection. Corpus gastritis before treatment was more severe in patients who subsequently developed reflux oesophagitis. In a similar study by Schütz et al, 10 of 16 patients with duodenal ulcer developed reflux oesophagitis after eradication of $H$ pylori $^{21}$

Several investigators have studied the association between $H$ pylori and GORD. ${ }^{22-29}$ Of eight trials, the six controlled trials yielded somewhat contrasting results. On the one hand, four studies observed no difference in the prevalence rate of $H$ pylori among patients with and controls without oesophagitis. ${ }^{24-27}$ On the other hand, two studies reported lower prevalence rates of $H$ pylori in patients with oesophagitis compared with controls without oesophagitis. $^{28}{ }^{29}$ These results seem to suggest that $H$ pylori does not play a major role in the pathogenesis of oesophagitis. Besides determining the presence of $H$ pylori, De Koster et al also studied the occurrence and distribution of gastritis in their biopsy specimens and found lower prevalence rates of corpus gastritis among patients with erosive oesophagitis. ${ }^{26}$ Our results suggest that the regional distribution and the severity of gastritis are the important risk factors in the pathogenesis of reflux oesophagitis rather than the mere presence of $H$ pylori in the gastric mucosa. The rates of infection with $H$ pylori in patients with and controls without reflux oesophagitis were similar. More patients than controls were treated with proton pump inhibitors. Therefore, any potential suppression of $H$ pylori by proton pump inhibitors would have affected patients with oesophagitis to a greater degree.

In a recent study of 132 patients infected with $H$ pylori, the presence of gastritis in the three regions of the stomach was strongly correlated. Gastritis of the antrum, corpus, and cardia was found in $100 \%, 94 \%$, and $98 \%$ of patients, respectively. In 14 patients with reflux oesophagitis, the grades of acute or chronic gastritis in the corpus were similar to those in the antrum and cardia. ${ }^{30}$ In a second study of 42 patients infected with $H$ pylori, Genta et al detected $H$ pylori organisms in $97 \%, 95 \%$, and $95 \%$ of antral, corpus, and cardiac biopsy specimens. A similar density of organisms was found in all three regions. There were strong correlations between the antrum and cardia regarding the type and severity of gastritis. Both acute and chronic gastritis were more prominent in the antrum and the cardia than in the corpus. ${ }^{31}$ We found the presence of both acute and chronic gastritis from different gastric sites to be significantly correlated. Acute and chronic gastritis represent variations in the mucosal response to mainly one disease 
process, namely, infection with $H$ pylori. Similarly, gastritis in different regions of the stomach reflects the spread and progression of $H$ pylori infection. The prevailing influence of one disease process is probably responsible for the clustering of different forms of gastritis in the same patients.

In conclusion, we found that acute and chronic corpus gastritis were significantly less common and less severe in patients with reflux oesophagitis than in controls. The infection rate of $H$ pylori was similar in the two groups. This pattern suggests that the distribution and severity of $H$ pylori related gastritis, rather than the mere presence or absence of $H$ pylori infection, play a role in the pathogenesis of reflux oesophagitis.

This study was supported by a Healthcare Advancement Award from the Glaxo Wellcome Institute for Digestive Health to $\mathrm{H} \mathrm{B}$ El-Serag and a grant from the Centres for Disease Control and Prevention to A Sonnenberg. The authors would like to thank David Kunkel for his help in data processing and Wallace Lee for his support in recruiting study patients.

1 Richter JE, Castell DO. Gastroesophageal reflux: pathogenesis, diagnosis, and therapy. Ann Intern Med 1982;97:93103 .

2 Lillemore KD, Johnson LF, Harmon JW. Role of the components of gastroduodenal contents in experimental

3 Vaezi MF, Singh S, Richter JE. Role of acid and duodenogastric reflux in esophageal injury: a review of animal and human studies. Gastroenterology 1995;108:1879907.

4 Collen NJ, Strong RM. Comparison of omeprazole and ranitidine in treatment of refractory gastroesophageal reflux disease in patients with gastric acid hypersecretion. Dig Dis Sci 1992;37:897-903.

5 Roher GV, Welsh JD. Correlative study: gastric secretion and histology. Gastroenterology 1967;52:158-91.

6 Bock OAA, Richards WCD, Witts LJ. The relationship between acid secretion after augmented histamine stimulation and the histology of gastric mucosa. Gut 1963;4:11214.

7 Savary M, Miller G. Der Ösophagus. Lehrbuch und endoskopischer Atlas. Solothurn, Switzerland: Gassman, 1977.

8 Dixon MF, Genta RM, Yardley JH, et al. Classification and grading of gastritis, the updated Sydney system. Am f Surg grading of gastritis, the upd

9 Hirschowitz BI. A critical analysis, with appropriate controls, of gastric acid and pepsin secretions in clinical controls, of gastric acid and pepsin secretions
esophagitis. Gastroenterology 1991;101:1149-58.

10 Hirschowitz BI. Gastric secretion of acid and pepsin in patients with esophageal stricture and appropriate controls. Dig Dis Sci 1996;41:2115-22.

11 Goldberg HI, Dodds WJ, Gee S, et al. Role of acid and pep$\sin$ in acute experimental esophagitis. Gastroenterology 1969;56:223-30.
12 Vaezi MF, Richter JE. Role of acid and duodenogastroesophageal reflux in gastroesophageal reflux disease. Gastroenterology 1996;111:1192-9.

13 Lillemore KD, Johnson LF, Harmon JW. Alkaline esophagitis: a comparison of the ability of components of gastroduodenal contents to injure rabbit mucosa. Gastroenterology 1983;85:621-8.

14 Cave DR, Vargas M. Effect of a Campylobacter pylori protein on acid secretion by the parietal cells. Lancet 1989;ii:187-9.

15 McGowan CC, Cover TL, Blaser MJ. Helicobacter pylori and gastric acid: biological and therapeutic implications. Gastroenterology 1996;110:926-38.

16 Tytgat GNJ. Role of $\mathrm{H}$. pylori in gastro-esophageal reflux. In: Hunt RH, Tytgat GNJ, eds. Helicobacter pylori, basic mechanisms to clinical cure 1996. Dordecht: Kluwer Academic Publishers, 1996:304-11

17 El-Omar EM, Penman ID, Ardill JE, et al. Helicobacter pylori infection in patients with duodenal ulcer disease. Gastroenterology 1995;109:681-91

18 El-Omar E, Oien K, El-Nujumi, et al. Helicobacter pylori infection and chronic gastric hyposecretion. Gastroenterology 1997;113:15-24.

19 Gutierrez O, Melo M, Segura AM, et al. Cure of Helicobacter pylori infection improves gastric acid secretion in patients with corpus gastritis. Scand 7 Gastroenterol 1997;32:664-8.

20 Labenz J, Blum AL, Bayerdörffer E, et al. Curing Helicobacter pylori infection in duodenal ulcer patients may provoke reflux esophagitis. Gastroenterology 1997;112: 1442-7.

21 Schütz K, Hentschel E, Dragosics B, et al. Helicobacter pylori reinfection with identical organisms: transmission by the patients' spouses. Gut 1995;36:831-3.

22 Cheng EH, Bermanski P, Silversmith M, et al. Prevalence of Campylobacter pylori in esophagitis, gastritis and duodenal disease. Arch Intern Med 1989;149:1373-5.

23 O'Connor HJ, Cunnane K. Helicobacter pylori and gastroesophageal reflux disease - a prospective study. Ir $\mathcal{F} \mathrm{Med} S c i$ 1994;163:369-73.

24 Newton M, Bryan R, Burnham WR, et al. Evaluation of Helicobacter pylori in reflux oesophagitis and Barrett's oesophagus. Gut 1997;40:9-13.

25 Vicari JJ, Falk GW, Goldblum JR, et al. H. pylori is not a pathogenic factor in GERD or its complications [abstract]. Gastroenterology 1997;112(suppl 1):A322.

26 De Koster E, Ferhat M, Deprez C, et al. Helicobacter pylori, gastric histology and gastro-oesophageal reflux disease [abstract]. Gut 1995;37(suppl 1):A36.

27 Blaser MJ, Perez-Perez GI, Lindenbaum J, et al. Association of infection due to Helicobacter pylori with specific upper gastrointestinal pathology. Rev Infect Dis 1991;13(suppl 8):S704-8.

28 Werdmuller BFM, Loeffeld RJLF. Helicobacter pylori infection has no role in the pathogenesis of reflux esophagitis. Dig Dis Sci 1997;42:103-5.

29 Mihara M, Haruma K, Kamda T, et al. Low prevalence of Helicobacter pylori infection in patients with reflux oesophagitis [abstract]. Gut 1996;39(suppl 2):A94.

30 Hackelsberger A, Günther T, Schultz V, et al. Prevalence and pattern of Helicobacter pylori gastritis in the gastric cardia. Am 7 Gastroenterol 1997;92:2220-4.

31 Genta RM, Huberman RM, Graham DY. The gastric cardia in Helicobacter pylori infection. Hum Pathol 1994;25:915- 